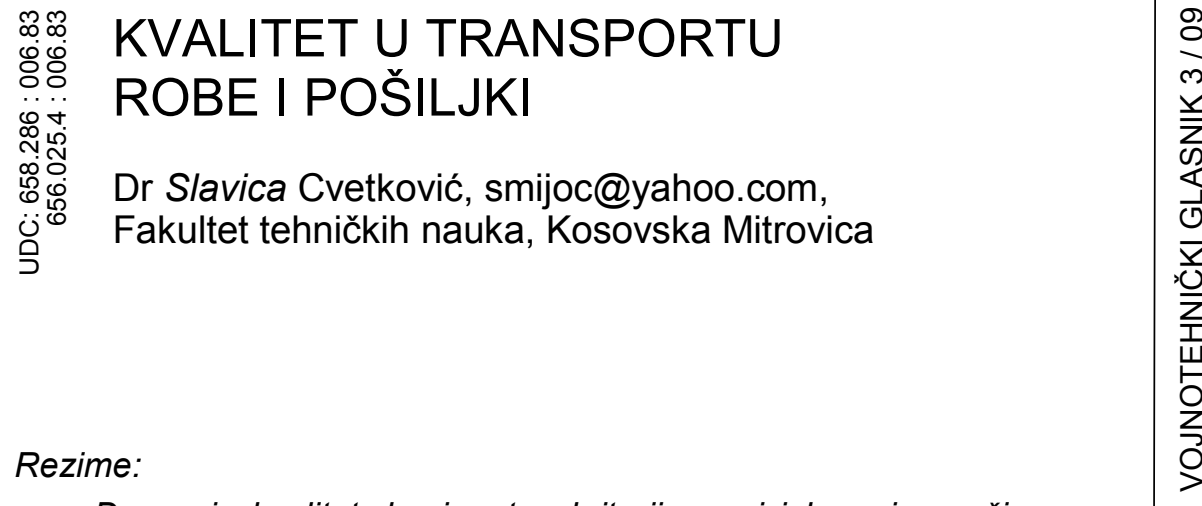

Danas je kvalitet dominantan kriterijum pri izboru isporučioca, a novi koncept kvaliteta smatra se superiornim metodom za reformu menadžmenta. Za razliku od tradicionalnog pristupa, novi koncept kvaliteta obezbeđuje povećanje prodaje uz istovremeno sniženje ukupnih troškova poslovanja. Obezbeđenje kvaliteta u skladu sa međunarodnim standardima serije ISO 9000 predstavlja uslov za nastup na svetskom tržištu i saradnju sa inostranim preduzećima.

Ključne reči: kvalitet, transport, logistika.

\title{
QUALITY OF PRODUCTS AND FORWARDED GOODS
} TRANSPORT

Summary:

When choosing a supplier today, a dominant criterion is quality, and a new concept of quality is said to be a superior method in the management reform. Unlike the traditional approach, the new concept of quality provides sales growth as well as a reduction in overall business expenses. Providing quality in accordance with the international standards series ISO 9000 is a condition to be fulfilled in order to enter the world market and cooperate with international companies.

Key words: quality, transport, logistics.

\section{Uvod}

Prema standardu ISO 8402 kvalitet se definiše kao: „Celokupnost karakteristika nekog entiteta, koje se odnose na njegovu sposobnost da zadovolji iskazane potrebe i potrebe koje se podrazumevaju“. Entitet može biti: aktivnost, proces, proizvod, kompanija, sistema, osoba ili bilo koja kombinacija navedenih izraza. U ovom radu govori se o transportu i kvalitetu transporta.

Transportna usluga je rezultat koji je proizišao iz niza aktivnosti prevoznika (operatora), počevši od stvaranja svih uslova za obavljanje transportne delatnosti (nabavka vozila, obezbeđenje finansijskih sredstava, odgovarajućih ljudskih resursa, itd.), preko planiranja transportnog procesa, pripreme vozila i osoblja, pa do izvršenja premeštanja robe ili putnika, 
u skladu sa njihovim zahtevima u pogledu obima, količine, rastojanja, kvaliteta: brzine, ritma, komfora, usluge, itd.

$U$ istim standardima kvalitet se definiše kao sveukupna svojstva - karakteristike usluge, koje se odnose na sposobnost davaoca (prevoznika) da zadovolje zahtevane i sve one potrebe korisnika koje se podrazumevaju.

Transportni sistemi, transportna tehnologija i transportna usluga imaju značajne specifičnosti u odnosu na druge proizvodno-tehnološke sisteme i proizvode. Osnovne karakteristike transportne tehnologije i transportne usluge su:

- putnik ili roba ne pripadaju proizvođaču - isporučiocu transportne usluge;

- višeparametarski karakter transportne usluge;

- pored obima i kvaliteta bitni parametri transportne usluge u odnosu na druge proizvode i usluge su prostor i vreme;

- istovremenost proizvodnje i trošenja usluge u prostoru i vremenu. Transportna usluga se mora pružiti, na mestu gde je i momentu kada je zahtev ispostavljen, u obimu i kvalitetu kako je zahtevano;

- pouzdanost funkcionisanja u pogledu obima i kvaliteta usluge transportnih sistema, kao organizacijsko-tehnoloških sistema, obezbeđuje se rezervisanjem kapaciteta vozila, a ne kao kod drugih proizvodno-tehnoloških sistema rezervisanjem proizvoda - usluga;

- završna kontrola kvaliteta, kao faktor pouzdanosti sistema, pre realizacije usluge nije moguća zbog pomenute osobine jednovremenosti isporuke i „trošenja“ usluge. Kontrola kvaliteta usluge obavlja se, dakle, jednovremeno sa „trošenjem“ usluge.

\section{Uloga i značaj transporta u društvu i okruženju}

Transport je delatnost od višestrukog i izuzetnog značaja i uticaja na okruženje. U oblasti društvene proizvodnje transport ima nekoliko značajnih uloga:

- kao podsistem logističke podrške svim proizvodnim procesima direktno utiče na rezultate svih primarnih i sekundarnih proizvodnih procesa. Naime, putem premeštanja objekata stvaraju se uslovi da se osnovni elementi proizvodnje (živi rad - ljudi, predmeti rada i sredstva za rad) nađu „na pravom mestu u pravom trenutku“;

- indirektno, kroz ostvaren kvalitet procesa izraženog kroz zamor ljudi ili oštećenja stvari, utiče na kvalitet i efektivnost tih procesa;

- kao privredna delatnost angažuje velika sredstva uložena u transportna vozila, živi rad, energiju, finansije i dr., i značajno je da ona posluje ekonomično.

Transport, takođe, utiče i na mogućnosti realizacije i drugih potreba ljudi. Svojim performansama i tehnologijom utiče na lokaciju, formu, veli- 
činu i kvalitet života u gradovima i vojnim objektima. Takođe, značajni su i uticaji transporta na okolinu.

Jedan od neželjenih koprodukata transporta su povrede i gubici života ljudi, kao i materijalni gubici i štete na transportnim vozilima i okolini usled saobraćajnih nezgoda kojih je sa povećanjem obima transporta svakog dana sve više.

Drugi negativan uticaj transporta na okolinu jeste stvaranje buke, zagađenje izduvnim gasovima i otpadnim materijama, što su neželjeni produkti transportne tehnologije.

Treći značajan uticaj ogleda se u tome da struktura i performanse transportnog sistema (brzina, kapacitet i cena, vidovna raspodela, itd.) bitno određuju racionalno korišćenje površina kao jednog od osnovnih prirodnih resursa, naročito u gradovima.

Transportni sistem takođe utiče na potrošnju energije koja potiče od prirodnih resursa (nafte, uglja, itd.), čije je racionalno trošenje vrlo značajno za svako društvo.

\section{Kvalitet usluga u transportu robe i pošiljki}

Da bi se obezbedila kvalitetna usluga i njeno stalno unapređenje prema standardima ISO 9001-4 neophodno je realizovati određene procese i dokumente koji ih prate.

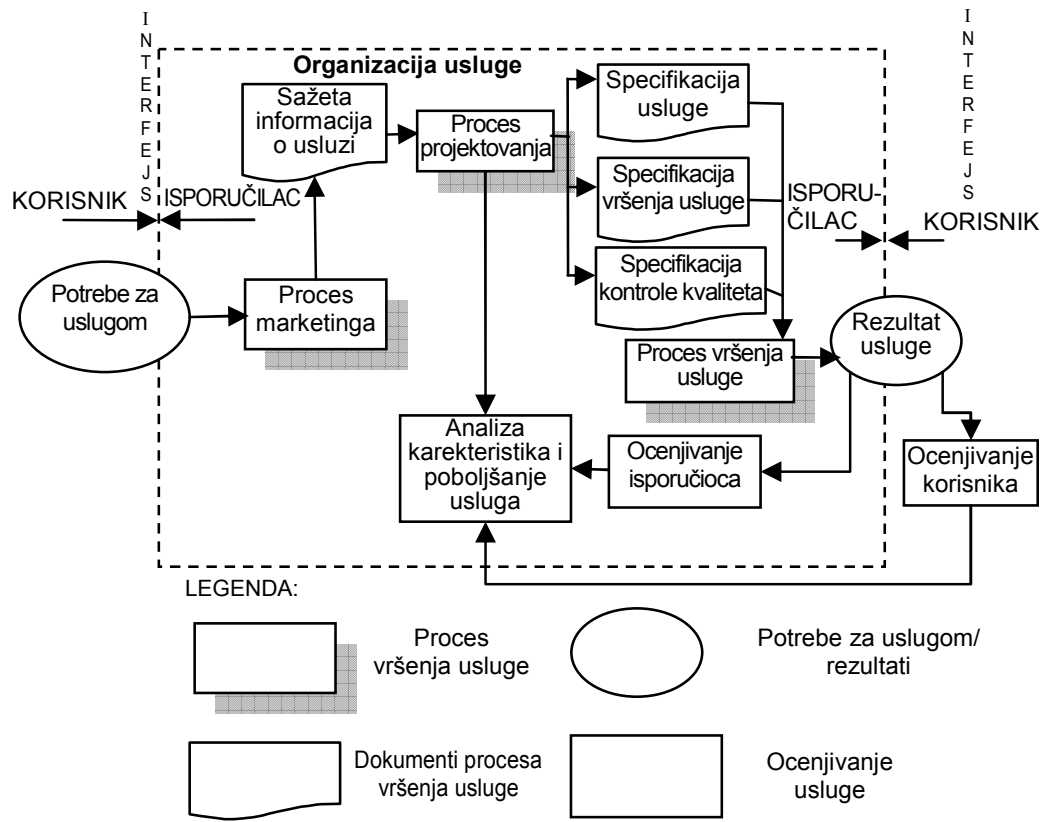

Slika 1 - Petlja kvaliteta pružanja usluge 
Osnovni procesi i dokumenti koji treba da prate obavljanje svake, pa i transportne usluge prikazani su u blok-dijagramu tzv. petlje kvaliteta (sl. 1).

Pod organizacijom transportnog procesa podrazumeva se niz usklađenih operacija, čiji je zadatak obavljanje transportne usluge. Da bi se uspešno organizovalo i upravljalo ovim složenim procesom, neophodno je da se prethodno sagledaju svi potprocesi i operacije u njemu, koje treba da budu usklađene sa petljom kvaliteta. Osnovni potprocesi i operacije u okviru transporta robe, odnosno pošiljki, uzimajući u obzir petlju kvaliteta TU, prikazani su na slici 2.

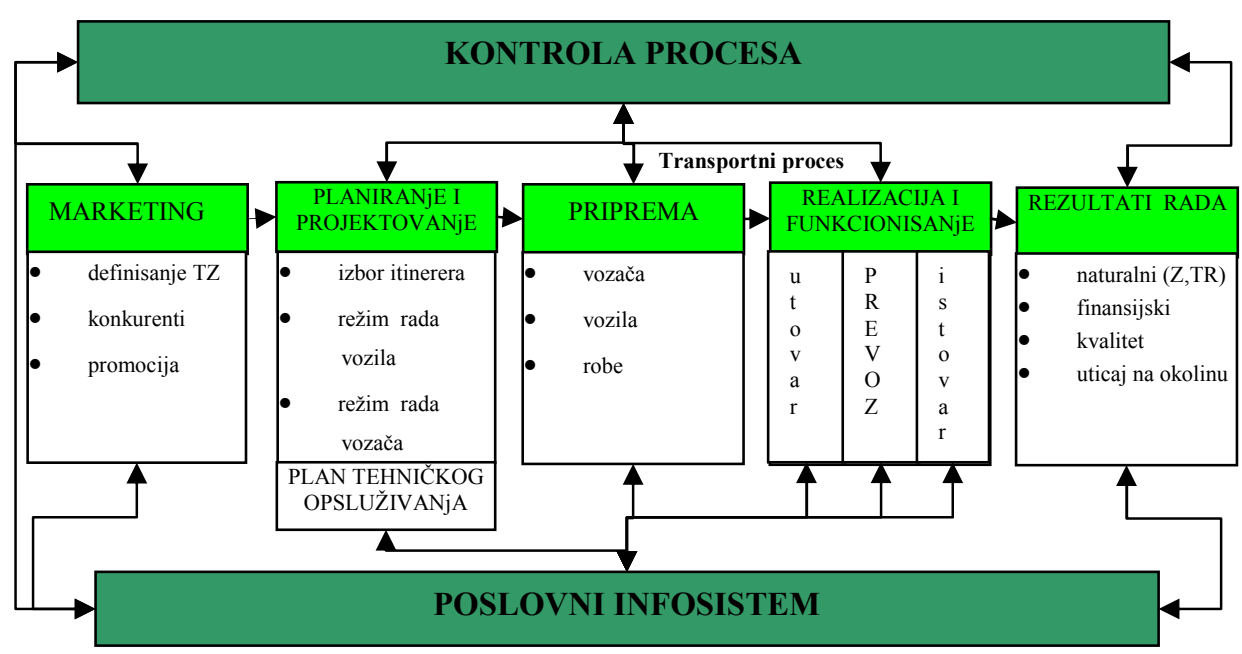

Okruženje

Slika 2 - Potprocesi i operacije u procesu transporta robe

\section{Potprocesi u transportu robe i pošiljki}

Kako se iz blok-dijagrama na slici 2 vidi, osnovni potprocesi u realizaciji transporta robe su: marketing; planiranje i projektovanje transportnog procesa; proces transporta; kontrola kvaliteta koju obavlja prevoznik; prikupljanje; memorisanje i obrada informacija; transportna usluga - obračun rezultata rada i učinka.

\section{Marketing}

Marketing obuhvata tri potprocesa:

- istraživanje i definisanje transportnih zahteva, usluga,

- istraživanje karakteristika najznačajnijih konkurenata na tržištu

- promociju i reklame transportnih usluga. 
Prva faza u organizaciji svakog transportnog procesa jeste da se utvrde konkretne vrednosti osnovnih svojstva i kvantitativni pokazatelji transportnih zahteva.

Pri definisanju kvantitativnih pokazatelja treba odrediti brojne vrednosti za količine robe - broj pošiljki koje treba transportovati, protoke i obim transportnog rada po vrstama roba, kao i ostale karakteristike tokova roba za svaki karakterističan period: po polascima, u toku dana, sedmice, sezone u toku godine, kao i njihovu raspodelu u prostoru (početne i završne tačke otpreme - prijema robe ili pošiljki).

Pri definisanju kvalitativnih pokazatelja transportnih zahteva potrebno je definisati zahteve u pogledu kvaliteta usluge i rangirati ih po značajnosti sa aspekta korisnika. Do definisanja zahteva dolazi se istraživanjem tržišta i, po mogućnosti, stvaranjem dugoročnih odnosa korisnika i prevoznika u kojima će biti precizirani svi elementi usluge u dužem periodu.

Ova aktivnost podrazumeva bliže definisanje performansi glavnih konkurenata, kako u pogledu ponuđenih kapaciteta, kvaliteta usluge, cena i sl. Izlazni rezultati iz ove faze u organizaciji transportnog procesa su transportni zahtevi merodavni za proračun potrebnih kapaciteta (vozila, ljudi, energije itd.) za izvršenje procesa.

\section{Planiranje i projektovanje transportnog procesa}

U okviru ovog potprocesa vrši se planiranje i projektovanje usluge:

- izbor optimalnog sistema kretanja vozila - itinerera,

- režim rada vozila i vozača,

- sistem tarifa, i

- plan rada tehničkog opsluživanja.

Organizacija kretanja vozila u toku rada treba da obezbedi najveći učinak - proizvodnost uz najmanji utrošak resursa (vozila, živog rada, energije). Pod itinererom (putanja, obrt, tura) podrazumeva se kretanje vozila u toku jednog ciklusa transportnog procesa od početne tačke puta (Us) do ponovnog povratka u istu tačku puta.

Obrt vozila sastoji se od više vožnji (kretanje vozila između svaka dva utovarno-istovarna mesta u toku jednog obrta vozila), koje mogu biti sa teretom ili bez njega.

Za utvrđivanje ukupnog učinka prevoznika uvek se polazi od učinka u toku svakog obrta vozila koji se sumiraju na nivou grupe vozila, podsistema i sl. Zbog toga je važno definisati osnovne pokazatelje rada vozila, počevši od jednog obrta vozila.

Osnovni pokazatelji rada jednog vozila u toku jednog obrta su:

- dužina itinerera - puta transporta $(K)$, koja predstavlja rastojanje koje vozilo pređe u toku jednog ciklusa kretanja. Dužina puta predstavlja zbir dužina pojedinih vožnji sa teretom $\left(\mathrm{K}_{\mathrm{ts}}\right)$ ili bez tereta $\left(\mathrm{K}_{\mathrm{ps}}\right)$, odnosno:

$$
K=\sum_{s} K_{t, s}+\sum_{s} K_{p, s}
$$


- vreme obrta $(T)$, koje predstavlja vreme trajanja ciklusa u okviru kojeg se obave sve operacije u toku jednog itenerera: kretanje vozila između krajnjih tačaka itinerera, i utovarno-istovarni procesi. Vreme obrta predstavlja zbir vremena provedenih vožnji $\left(\mathrm{t}_{\mathrm{w}}\right)$ i na utovaru-istovaru ( $\left.\mathrm{t}_{\mathrm{ui}}\right)$, odnosno:

$$
T=\sum t_{u i}+\sum t_{w}
$$

- broj obrta u toku rada $\left(n_{0}\right)$, koji predstavlja broj ponovljenih ciklusa u toku rada vozila i dobija se iz odnosa vremena vozila na radu i vremena obrta:

$$
n_{o}=\frac{H_{r}}{T},
$$

- broj vozila na radu (N),

- nosivost - kapacitet jednog vozila (Cv),

- količina transportovane robe, odnosno broja pošiljki u toku jednog obrta vozila $(P)$.

Količina transportovane robe $u$ toku jednog obrta vozila predstavlja zbir količina roba transportovanih u pojedinim vožnjama (Us), odnosno:

$$
P=\sum U_{s} \text {. }
$$

$S$ druge strane, količina robe, odnosno pošiljki koje može da preveze jedno vozilo u toku vožnje jednaka je proizvodu između nosivosti vozila $(C v)$ i iskorišćenja te nosivosti $\left(\gamma_{s}\right)$ :

$$
Z_{S}=C_{V} \cdot \gamma_{S},
$$

pa je količina transportovanih pošiljki u toku jednog obrta:

$$
P=C_{V} \cdot \sum_{S} \gamma_{S} \text { (tona). }
$$

Iz prethodnih jednakosti se vidi da iskorišćenje korisne nosivosti vozila predstavlja odnos između nosivosti vozila i prevezene količine robe, odnosno:

$$
\gamma_{S}=\frac{Z_{S}}{C_{V}} \quad\left(0<\gamma_{s}<1\right)
$$

Obavljeni transportni rad (NTR) predstavlja proizvod između transportovane količine robe, odnosno pošiljki i rastojanja prevoza i može se izračunati:

- za jednu vožnju (NTRs):

$N T R_{s}=Z_{s} \cdot l_{s}(\mathrm{t} \cdot \mathrm{km})$,

- za jedan obrt (NTR) kao zbir izvršenog transportnog rada u pojedinim vožnjama:

$$
N T R=\sum N T R_{s}=\sum Z_{s} \cdot l_{s}(\mathrm{t} \cdot \mathrm{km}) .
$$


Ponuđeni transportni rad (BTR) predstavlja proizvod između ponuđenog kapaciteta vozila (Cv) i dužine transporta i može se izračunati:

- za jednu vožnju:

$$
B T R_{s}=C_{V_{s}} \cdot l_{s}(\mathrm{t} \cdot \mathrm{km}) \text {. }
$$

za jedan obrt vozila:

$$
B T R=\sum B T R_{s}=\sum C_{V_{s}} \cdot l_{s}(\mathrm{t} \cdot \mathrm{km}) .
$$

Zaključak

Za izvršenu transportnu uslugu korisnici plaćaju određenu nadoknadu, čija je visina unapred definisana tarifnim sistemom ili međusobnim dogovorom isporučioca i korisnika usluge koji se utvrđuje ugovorom.

$U$ transportu se cena usluge određuje se prema izvršenom učinku i zavisi, najčešće, od dužine (distance) transporta. Tarifni sistem predstavlja uređen sistem po kojem se određuje visina naknade za izvršene transportne usluge.

Za korisnika tarifni sistem predstavlja spisak cena za pojedine vrste usluga, a za prevoznika to je složen sistem koji obuhvata: izbor tipa tarifnog sistema koji će biti primenjen, određivanje tzv. osnovne cene (tarifnog modula), izbor tarifnih koraka, vrste i visine popusta za određene kategorije korisnika, itd.

U toku eksploatacije dolazi do promene tehničkog stanja vozila. Osnovni procesi koji utiču na promenu tehničkog stanja podsklopova, sklopova i vozila su: trenje, korozija, zamor i starenje materijala od kojih je vozilo sačinjeno. Intenzitet ovih procesa zavisi od kvaliteta vozila (ugrađena svojstva vozila), uslova eksploatacije (opterećenja, usponi, vlaga, itd.) i intenziteta eksploatacije (časovi vozila u radu).

\section{Literatura}

[1] Internet: Computerised Vehicle Routing and Scheduling (CVRS) for Efficient Logistics Freight Best Practice, DfT (Department for Transport), 2005, UK,

[2] Marinković, Z., Skladišna tehnika - autorizivana predavanja, MF Niš, 2003. 2005.

[3] Filipović, S., Osnovi tehnologije transporta, Saobraćajni fakultet Beograd,

[4] Jovanović, A., Operaciona istraživanja, Rudarsko-metalurški fakultet Bor, 2005.

[5] Špagnut, D., Tehnološke osobine transportne robe u prevozu, Saobraćajni fakultet Beograd, 1989.

[6] Cvetković, S., Barac, N., Milovanović, G., Poslovna logistika (zbirka rešenih zadataka), Niš 2004. 